\begin{tabular}{|l|l|}
\hline & \\
&
\end{tabular}

\title{
Desafios e possibilidades para o controle social de políticas públicas no atual contexto de retrocesso dos direitos sociais
}

Challenges and possibilities for social control of public policies in the current background of social rights

Vini Rabassa da Silva ${ }^{1}$ orcid.org/0000-0003-3684-8719 vini.silva@ucpel.edu.br

\section{Mara Rosange Acosta de Medeiros ${ }^{1}$}

orcid.org/0000-0003-0764-8670 mara.medeiros@ucpel.edu.br

Recebido em: 31/12/2019 Aprovado em: 4/6/2020 Publicado em: 30 out. 2020.

\section{(c) (1)}

Artigo está licenciado sob forma de uma licença Creative Commons Atribuição 4.0 Internacional.
Resumo: O artigo pretende retomar a importância do exercicio do controle social democrático de políticas públicas, problematizando o seu alcance em um Estado capitalista, autoritário e conservador, a fim de estimular processos participativos no âmbito das políticas sociais, que simultaneamente lutem pela ampliação de direitos sociais na perspectiva emancipatória e ampliem a consciência coletiva e a organização popular. Primeiramente, apresenta-se uma visão das políticas públicas no contexto atual, posteriormente os desafios para o exercicio do controle social democrático, finalizando com a indicação de algumas possibilidades estratégicas para a sua efetivação.

Palavras chave: Politicas públicas. Participação. Conselhos. Controle social democrático.

Abstract: The aim of this text is to resume the importance of the exercise of democratic social control of public policies, problematizing its reach in a capitalist, authoritarian and conservative state, to stimulate participatory processes within the social policies, which simultaneously strive for the expansion of social rights from an emancipatory point of view and broaden the collective consciousness and popular organization. First, we present a vision of public policies in the current context, then the challenges for the exercise of democratic social control, ending with the indication of some strategic possibilities for its implementation. Keywords: Public policies. Participation. Councils. Democratic social control.

\section{Introdução}

O exercício do controle social de políticas públicas foi inserido na sociedade brasileira oficialmente com a Constituição Federal de 1988, para ser efetivado precipuamente por meio de conselhos, isto é, de órgãos representativos dos setores governamental e não-governamental, ou da sociedade civil organizada. Portanto, é decorrência de uma reforma do Estado, a qual, paralelamente à descentralização político-administrativa, inclui a participação da sociedade civil na administração pública. Os conselhos, como mecanismos de controle social, chegaram a ser considerados uma das maiores inovações políticas na década de 1990 (GOHN, 2001).

Entretanto, a possibilidade da eficácia desse tipo de controle social sempre foi objeto de questionamento e até mesmo de total descrédito. Por ocasião das reflexões feitas no Seminário Nacional "O Controle Social e a Consolidação do Estado Democrático de Direito", promovido pelo Conselho Federal de Serviço Social (CFESS), Maria Inês Bravo apresentou três concepções distintas em relação aos conselhos. 
A primeira, baseada na concepção de Gramsci, reconhece-os como espaços contraditórios, permeados pela tentativa do capital de anular a expressão popular, mas capazes de obterem conquistas favoráveis aos interesses da classe subalterna, por meio de confrontos com os setores dominantes. A segunda concepção, que segundo a autora é utópica ou voluntarista, considera-os como mecanismos de obtenção de consenso entre os diferentes setores representados. Finalmente, a terceira não reconhece nos conselhos qualquer potencial e recomenda a não participação nesses espaços (BRAVO, 2011).

Diante dessas três concepções, convém destacar que a expressão controle social jamais chegou a superar plenamente a marca de sua origem histórica, associada ao controle estatal, por meios coercitivos ou persuasivos, sobre a sociedade (SILVA et al., 2008), com a qual foi amplamente identificada até o início dos movimentos pela democratização do Estado na década de 1980. Assim, apesar de a Constituição Federal de 1988, ao instituir o Estado Democrático de Direito, ter revertido a sua concepção, passando a compreendê-lo como o controle da sociedade sobre o Estado, como um dos elementos caracteristicos do regime democrático, ainda hoje constata-se a forte presença da concepção anterior ao esforço de democratização empreendido por parte da sociedade civil organizada.

Apesar disso, entendemos que a trajetória percorrida pelos conselhos, como principais mecanismos de controle social democrático, foi traçando uma diferenciação mais objetiva sobre o significado de controle social. Enquanto alguns setores simplesmente os ignoraram, outros insistiram na sua importância e na necessidade de maior qualificação de conselheiros, a fim de melhor exercerem o controle das ações do Estado, por meio do monitoramento e da fiscalização de políticas públicas, com o objetivo de direcioná-las ao atendimento de interesses das classes subalternas.

Em consequência dessa dinâmica, na atualidade, pode-se perceber que o exercício do controle social democrático de políticas públicas por meio de conselhos é compreendido de duas maneiras distintas: a) como meio de manipular a participação popular, tendo em vista o convencimento da classe subalterna para legitimar decisões políticas, sendo ignorado ou criticado de forma destrutiva por setores das forças progressistas; b) como meio de disputa de interesses divergentes que, dependendo da correlação de forças estabelecida, pode obter, ou não, conquistas para os setores populares.

A passagem dos 100 dias do Governo Bolsonaro, em abril de 2019, foi marcada, entre outras ações, pela promulgação do Decreto presidencial $n^{\circ}$ 9.759, que extinguiu todos os conselhos que não foram criados por Lei. Esse ato implicou na redução de 700 Conselhos Federais para 50, sob o pretexto de redução de custos com a manutenção de estruturas inúteis.

Apesar dos devastadores efeitos do Decreto, ainda restaram preservados vários conselhos da área das políticas sociais (assistência social, saúde, meio ambiente, segurança alimentar, entre outros). Ademais, dois conselhos extintos pelo Decreto (conselho da pessoa com deficiência e conselho do idoso), graças à mobilização da sociedade civil, foram recriados. Com isto, o potencial político dos conselhos é novamente colocado na pauta das discussões, desta feita por um governo explicitamente contrário à participação social no âmbito da gestão governamental.

É dentro desse contexto que queremos destacar a necessidade de retomar a importância da participação popular e do controle social como estratégias de resistência ativa frente ao retrocesso democrático e ao avanço do conservadorismo comprometido com o capital internacional.

Para isso, primeiro abordaremos a questão das políticas públicas, particularmente as sociais, no atual contexto brasileiro demarcado por aspectos estruturais e conjunturais que incidem sobre elas, complexificando cada vez mais o seu já limitado potencial emancipatório dentro dos limites do capitalismo. Posteriormente, indicaremos alguns desafios e possibilidades para a participação popular e controle social dessas politicas em uma conjuntura social e política marcada pela pós-verdade e pelo autoritarismo.

Sendo assim, esperamos com este texto con- 
tribuir para uma problematização que estimule o empreendimento de esforços, a fim de qualificar e intensificar a participação popular e o controle social democrático, como mediações para uma transformação social radicalmente comprometida com a extinção da crescente desigualdade social que grassa na sociedade brasileira, associada transversalmente às discriminações negativas de gênero e étnico-racial.

\section{As políticas públicas no contexto atual}

Entendemos as políticas públicas, conforme explicitado por Geraldo Di Giovanni.

Tal conceito vai além da ideia de que uma política pública é simplesmente uma intervenção do Estado numa situação social considerada problemática. Mais do que isso, penso a política pública como uma forma contemporânea de exercício do poder nas sociedades democráticas, resultante de uma complexa interação entre o Estado e a sociedade, entendida aqui num sentido amplo, que inclui as relações sociais travadas também no campo da economia. Penso, também, que é exatamente nessa interação que se definem as situações sociais consideradas problemáticas, bem como as formas, os conteúdos, os meios, os sentidos e as modalidades de intervenção estatal (GIOVANNI, 2009, s/p).

Portanto, em sentido amplo, as politicas públicas são intervenções do Estado, que podem ser dirigidas tanto ao campo econômico, como administrativo e social. Assim, elas incluem as denominadas políticas sociais, isto é, aquelas direcionadas ao enfrentamento das diferentes manifestações da questão social e nas quais o Estado brasileiro permite, também, a participação de outros setores de diversas modalidades e intensidades.

Em decorrência, as políticas sociais, além de serem constituidas e desenvolvidas pelo Estado, podem ser desenvolvidas pelo mercado, isto é, pelo conjunto de empresas e associações que exercem atividades privadas, com fins lucrativos; ou ainda, pela sociedade civil organizada, isto é, por organizações não governamentais, que visam resolver problemas sociais coletivos, sem extrair lucro com o desenvolvimento de suas atividades. E, quanto mais o Estado se afasta de responder a problemas sociais coletivos, mais os outros dois setores se organizam para dar respostas a eles.
Durante o ciclo de desenvolvimento das politicas, esses três setores podem agir de forma autônoma, como agentes complementares ou como competidores, como opositores ou como aliados. A resposta planejada de forma técnica, com ou sem a participação dos sujeitos diretamente afetados pelo problema, a execução das ações previstas nos planos, programas e projetos, o monitoramento e a avaliação para capturar informações que subsidiarão a avaliação final da atividade, indicando o seu êxito e conclusão, ou a necessidade de continuidade com ou sem reformulações, são momentos do processo de desenvolvimento das políticas, que podem ser de responsabilidade exclusiva, ou compartilhada por mais de um setor.

Independente do responsável pela política (estado, mercado ou sociedade civil organizada), ela sempre deverá passar por uma avaliação para verificar a eficiência na aplicação de recursos e se foram eficazes na resolução do problema. Essa avaliação requer um acompanhamento do desenvolvimento das ações previstas, o qual pode ser o conteúdo substantivo do controle social.

Desde já, portanto, convém alertar que a avaliação de uma política nunca será feita de modo imparcial ou com neutralidade, pois os critérios de análise vão ser determinados pelos interesses do/a avaliador/a. Dessa forma, para o gestor, a política pode ser considerada excelente, por ter requerido um orçamento limitado, enquanto para o público a quem se dirigiu, poderá ser considerada negativa pelo mesmo motivo, significando que para os usuários ela não atenderá as suas expectativas.

Até este momento estamos tratando de aspectos pragmáticos de políticas públicas, que definem, de modo geral, para que finalidade elas existem, quem pode ser responsável ou responsabilizado pelo seu desenvolvimento, bem como a relatividade inerente a sua avaliação. Porém, o que de fato determina a necessidade, a finalidade e o alcance efetivo das políticas públicas é um complexo de determinações econômicas, políticas e sociais, que interagem sob o comando de elementos estruturais e conjunturais. Por isso, o conhecimento da totalidade é fundamental, tanto para uma projeção direcionada à erradicação do problema que a originou, como para a sua 
avaliação. E, nessa perspectiva, vale lembrar que a direção de uma política pública produz e reproduz o direcionamento das outras, ainda que sejam de natureza diferente, pois a raiz estruturante refratará em todo o conjunto de políticas emanadas de um mesmo bloco de poder.

Podemos tomar como exemplo a política ambiental. A realidade vivida nesta segunda década do novo milênio põe em evidência a crise climática planetária, com suas repercussões mundiais, com previsão de uma catástrofe climático-ambiental de consequências imprevisiveis possivelmente antes de 2050, segundo estudiosos de questões ambientais, caso as propostas apontadas pela comunidade científica internacional continuem sendo ignoradas. Portanto, não se trata meramente de uma questão ambiental, mas também política, pois a negativa da adoção de várias recomendações para preservar o meio ambiente decorre da priorização pelos Estados nacionais da manutenção do lucro de grandes corporações em detrimento da garantia do equilibrio climático e ecológico.

Assim, assistimos aqui no Brasil sinais do esgotamento da natureza ${ }^{2}$ diante da ferocidade humana, com a proliferação de queimadas, desmatamentos, rompimento de barragens. Portanto, a crise ambiental é uma das manifestações das consequências desastrosas da mundialização do capital associada à financeirização da economia mundial, demarcando uma era em que a esfera da produção (indústria, agricultura e comércio), considerada por muito tempo como única força motriz do capital, movimenta menos dinheiro do que a bolsa de valores, mercado de títulos, entre outros tipos de transação financeira, trazendo consequências destrutivas ao mundo do trabalho.

Paralelo ao processo de mundialização e reestruturação do capital, deu-se um processo de expansão mundial da superpopulação relativa que tem permitido aos diversos capitalistas garantir seus "superlucros" graças aos salários baixos proporcionados pela imensa massa de trabalhadores disponíveis no mercado mundial" (LARA e MARANHÃO, 2019, p. 59).

Em consequência, em países periféricos como o Brasil, a desigualdade de renda vem aumentando consecutivamente desde 2015. No primeiro trimestre de 2019, atingiu o maior patamar já registrado desde o começo da série histórica, criada em 2012, tendo o índice de Gini ${ }^{3}$ alcançado 0,627 em março daquele ano.

A mudança política ocorrida com a troca do governo popular por um de extrema direita significou a implementação de uma política econômica subserviente aos interesses do grande capital, conjugada ao uso de diversos meios para afastar da política os setores progressistas dos partidos politicos e os movimentos sociais (MST, MTST, indigenas, negros, LGBT e outros) identificados com a defesa de interesses das classes subalternas. Em outras palavras, a economia submissa ao grande capital internacional anda de mãos dadas com uma classe política dirigente que usa a repressão, a coerção, o fundamentalismo religioso e as tecnologias sociais para anular movimentos em defesa das classes subalternas e criar uma concepção anti-intelectualista, apostando na eliminação dos intelectuais orgânicos de esquerda e na extinção das classes trabalhadoras como agente político.

Para isso, a exemplo do que vem ocorrendo em outros países, o apelo aos sentimentos e à crença pessoal são usados e tornam-se mais importantes do que a objetividade dos fatos, de tal forma que a verdade é relativizada e o uso das redes sociais permite que notícias falsas sejam divulgadas como verdadeiras e conquistem adeptos, evidenciando a presença do fenômeno da pós-verdade ${ }^{4}$, que contribui para disseminar a relativização do que de fato ocorre. Diante desse

\footnotetext{
2 O Fundo Mundial para a Natureza, ONG de defesa do meio ambiente, que reúne pesquisadores do mundo inteiro, divulgou em 2018 , no relatório Planeta Vivo, que desde 2070, o Brasil já havia reduzido 20\% da Floresta Amazônica e 50\% do Cerrado (VEIGA, 2018).

3 O índice de Gini foi criado para medir a desigualdade social de um país, estabelecendo uma escala de o (ausência de desigualdade) a 1 (máxima desigualdade). Portanto, quanto mais o país se aproximar de 1, maior será o índice de desigualdade existente.

4 Na coletânea Psicologia, Comunicação e Pós-Verdade. André Guerra e Claudia Barbosa, ao analisarem o significado de pós-verdade. apresentam, entre outras, a seguinte definição do Dicionário Priberam, de Portugal: Conjunto de circunstâncias ou contexto em que é atribuida grande importância, sobretudo social, política e jornalistica, as notícias falsas ou a versões verossimeis dos fatos, com apelo às emoções e às crenças pessoais, em detrimento de fatos apurados ou da verdade objetiva (ex. a mentira e os boatos alimentam a pós-verdade; o tema do momento é a pós-verdade nas redes sociais). (GUERRA E BARBOSA, 2018, p. 136)
} 
cenário traçado de forma geral, cabe perguntar: - Ainda há possibilidade para o exercício do controle social democrático de políticas públicas? Isto é, a participação da sociedade civil pode interferir na gestão pública de políticas sociais, fiscalizando o uso de recursos e a qualidade dos serviços prestados no atual contexto, exigindo a ampliação e sua qualificação?

Entendemos que sim, sem a ilusão de que essa representação será capaz de significar o elemento decisivo para a existência de políticas públicas resolutivas de manifestações da questão social, o que aliás nunca chegaram a ser. Todavia, sim, entendendo o exercício do controle social como uma estratégia de luta e de resistência no campo das políticas sociais pela emancipação5, que favoreça o acúmulo de forças para a construção de um novo projeto societário, considerando que "é no seio das relações de forças políticas que a homogeneidade, a autoconsciência e a organização dos diferentes grupos podem se desenvolver" (SIMIONATTO, COSTA, 2014, p.69). Mas, certamente, essa construção necessitará enfrentar maiores desafios, tendo em vista o retrocesso ocorrido em relação à conquista de direitos sociais.

\section{Desafios para o controle social democrático das políticas públicas}

O Brasil, após um período de governos populares, encontra-se, no âmbito das políticas sociais, envolto em velhas e novas contradições.

O grande desmonte de direitos sociais que vem ocorrendo como a reforma trabalhista, reforma da previdência, corte de financiamento de conferências nacionais da saúde e da assistência social, revisão do Benefício de Prestação Continuada (BPC), associado ao não pagamento do funcionalismo público, à onda de privatizações, aos ataques aos territórios indigenas e quilombolas, ao aumento de manifestações racistas e homofóbicas, à escola sem partido, ao cerceamento da liberdade das universidades, ao desmatamento da Amazônia, aos ataques aos defensores de Direitos Humanos, enfim, a multiplicação da barbárie cria tantos chamados para mobilizações populares que se corre o risco de pulverizar forças, gerando um perverso enfraquecimento das lutas populares. Diante disso, é preciso discernimento crítico para descobrir não só como manter a resistência, mas também como fortificar e unificar as lutas populares, pois mesmo alguns excluidos foram sendo conquistados com os falsos apelos à defesa da família, dos valores sagrados e da segurança e liberdade individuais, nobres bens supostamente ameaçados por uma ideologia de esquerda que precisa ser combatida.

Outro embuste criado para o convencimento das massas é de que o caos econômico que assola o País, impedindo até o cumprimento do pagamento dos salários dos servidores públicos, é decorrente do excesso de gasto com direitos sociais, inclusive com a manutenção de organismos responsáveis pelo exercício da democracia semidireta, como conselhos nacionais.

Assim, permeado por estratégias coercitivas e de persuasão, sustentado pelo sistema econômico internacional e por uma política apoiada na pós-verdade, o Brasil vive um momento complexo e avesso a qualquer expressão de interesses populares.

\begin{abstract}
Assiste-se hoje o que Coutinho (2010), inspirado em Gramsci, chamou de pequena política. Ou seja, a redução da política a disputas de poder de frações de uma mesma classe que se envolve, cotidiana e quase exclusivamente, em intrigas, politicagens, "política de corredor", debates parciais. A sandice, para usar um termo de Santos (2017), que tomou conta do Brasil e a letargia de parcela significativa da população contribuem para essa derrocada (PEREIRA, 2017, p. 28).
\end{abstract}

Os elementos estruturais e conjunturais traçados anteriormente constituem o pensamento hegemônico de insustentabilidade da proteção social pública e, consequentemente, da necessidade de que a proteção seja uma responsabilidade familiar e individual, após a conquista da maioridade civil.

O breve avanço obtido pela sociedade brasileira em relação aos direitos sociais, após a Constituição Federal de 1988, é atingido pela intensificação da lógica do Estado mínimo, conduzindo à extin- 
ção da proposta de universalidade das políticas sociais, substituindo-a por políticas residuais.

O campo das políticas sociais, cada vez mais, vai sendo restringido à focalização nas populações que vivem na miséria e que são consideradas incapazes de obterem melhores condições de sobrevivência. Tal restrição esvazia a noção de direito social, apoiada pela redistribuição da riqueza socialmente produzida. A prestação de serviços sociais tende a ser identificada novamente como benesses ofertadas a pessoas e grupos incapazes de produzirem o próprio sustento. Aos demais grupos sociais ameaçados pela pobreza há um forte incentivo ao desenvolvimento do protagonismo e do empreendedorismo, como se por esses meios fosse possivel exercitar a fábula do Barão de Münchhausen. ${ }^{6}$

Vai se consolidando, cada vez mais, a ideia de uma política pobre para os pobres e de uma política de primeira classe para quem pode pagar, com o avanço crescente de planos privados de saúde e de previdência. E isso amplia o leque da mercadorização das políticas sociais, que toma conta, também, da proteção social para idosos e para crianças, por meio das instituições de longa permanência para idosos (ILPIs) e das escolas de educação infantil desenvolvidas pela iniciativa privada, que oferece serviços diferenciados de acordo com o pagamento de mensalidades.

Paralelamente, crescem as exigências para o acesso aos benefícios e serviços sociais, sob a alegação de que devem ser dirigidos a quem merece. Assim, acabam pautados por certa forma de meritocracia, que é definida pelo enquadramento dos individuos aos critérios estabelecidos para o acesso, e pela obediência aos padrões fixados pelo Estado para a permanência como usuário.

Enfim, esses são impactos causados pelo Estado brasileiro nas politicas sociais, que, embora não sejam totalmente novos no amplo e complexo campo da proteção social, trazem a nova marca do conservadorismo autoritário. Ao mesmo tempo em que retira direitos sociais, produz a multiplicação de indivíduos e grupos, que sobrevivem em condições sub humanas e ameaçados pelo extermínio de segmentos sociais e territoriais, considerados não funcionais ao padrão social vigente.

De fato, conforme analisado por Prates,

$$
\begin{aligned}
& \text { potencializar o caráter emancipatório das po- } \\
& \text { liticas, a partir da ampliação de estratégias } \\
& \text { que instiguem a mobilização, a consciência, } \\
& \text { a organização, o acesso à informação mais } \\
& \text { qualificada, decodificada, que amplia a cadeia } \\
& \text { de mediações da população, tem sido um dos } \\
& \text { grandes desafios a ser, ainda, conquistado } \\
& \text { no âmbito das politicas públicas, pois são } \\
& \text { processos fundamentais à participação e à } \\
& \text { efetiva democratização das politicas públicas } \\
& \text { (PRATES, 2015, p. 4). }
\end{aligned}
$$

O desafio apontado continua existindo mesmo após o giro à direita feito pelo Brasil. Ainda que a realidade seja totalmente adversa ao seu enfrentamento, o movimento contraditório incessante da realidade também mantém possibilidades para o exercício da participação e do controle social de políticas públicas, que precisam ser exploradas.

Dentro deste cenário estão situados os conselhos de políticas públicas, cujo funcionamento é atravessado por muitas dificuldades. Ocorre, frequentemente, da representação da sociedade civil ter de confrontar-se com o uso de competências burocráticas por parte de técnicos integrantes do setor governamental, em um jogo de manipulação política de interesses de grupos presentes na gestão mista das políticas sociais, que pretende se impor, usando a máscara da burocracia para disfarçar o uso do poder autoritário sob a capa da neutralidade técnica.

Faltam condições materiais para o pleno funcionamento democrático (muitos conselhos municipais não têm local adequado de funcionamento e usam de espaços sem privacidade para o debate de questões, expondo os conselheiros perante as autoridades públicas diretamente relacionadas àquela política, como secretários, chefe de gabinete e o próprio prefeito e/ou vice). Além desses problemas estruturais no funcionamento, há muitos outros que concorrem para a sua debilidade, como fraca participação

\footnotetext{
- A referida fábula conta que um Barão conseguiu se salvar, após cair com o seu cavalo em cima de um fosso de lama, puxando seu próprio cabelo para cima e segurando o cavalo com suas pernas, até conseguir chegar à margem do fosso.
} 
e despreparo para o exercício da função, falta de disponibilidade dos conselheiros, ausência de assessoria técnica, falta de transparência da gestão, inexistência de uma cultura política de participação na gestão pública, entre outros.

Apesar disso, os conselhos têm obtido muitas conquistas, incluindo a correção ou prevenção de desvios financeiros ou de procedimentos prescritos para a execução pela rede de serviços. Entre os resultados positivos de resultantes da sua atuação podem ser citadas a garantia de leito para internação de pacientes do SUS em hospitais da rede conveniada; a reestruturação de serviços de acolhimento para crianças e adolescentes; o fechamento de Instituições de Longa Permanência para Idosos por violação de direitos dos usuários, ou a reestruturação do serviço; a denúncia do não cumprimento de metas previstas nos Planos Municipais e constantes do relatório anual; entre outras. Ademais, não se pode deixar de fazer referência à importante e permanente luta pela manutenção do SUS e do SUAS.

Uma das grandes evidências do importante papel desempenhado pelos conselhos, enquanto espaços abertos à participação e responsáveis por estender a participação nas bases municipais, é o fato de, a despeito de suas ambiguidades e fragilidades, sofrerem ataques da parte de governantes conservadores, centralizadores e autoritários, nas diferentes instâncias federativas (municipios, estados, distrito federal e união).

Por outro lado, esse movimento de ampliação da participação por meio dos conselhos não tem caminhado em consonância com a criação de mecanismos locais de participação nas politicas sociais, tais como conselhos locais em UBSs ou comissões locais nos CRASs. Essa lacuna ocasiona o distanciamento das bases populares dos conselhos, evidenciado pelo pouco reconhecimento de sua ação pela comunidade, bem como pela sua não valorização por parte dos usuários. Esse distanciamento das bases, representadas no seu interior, reflete no seu enfraquecimento político e no risco de se tornarem um mecanismo elitista de participação, cujas ações, ainda que positivas, não conseguem reforçar o campo emancipatório dos usuários.
Observa-se, também, que vários outros serviços socioassistenciais, ou da rede de saúde, possibilitam a participação de usuários em atividades socioeducativas. Elas, no entanto, algumas vezes deixam de ser realizadas pela falta de tempo dos profissionais e/ou técnicos, bem como pela ausência de condições materiais para a sua execução. Existem, ainda, ações que quando são realizadas não contam com a participação dos usuários, exatamente pela sua condição concreta de vulnerabilidade social, que implica na canalização de sua pouca energia em prol da busca concreta de sobrevivência, que perversamente lhes retira, totalmente, o tempo para dedicar à sua "vivência plena" como ser humano. É o ciclo perverso da manutenção da subalternidade - a pessoa não participa, porque é subalterna e, porque não participa, aprofunda a subalternidade.

O momento atual, conforme pincelado na apresentação, acirra esses limites, tendo em vista os aspectos socioeconômicos, políticos e culturais que o constituem e que vão formando um caldo de reações irracionais, expresso pela crescente violência e disseminação do ódio, associadas à adesão ao caminho único da prevalência da ordem do capital e a manutenção de tudo que contribui para a sustentação do sistema vigente. Assim, o colonialismo, o patriarcado e o racismo estão imbricados com os limites estruturantes da falta de condições para o exercício do controle social democrático, devido aos valores de submissão e de obediência que transmitem. Dessa forma, para buscar romper com esses determinantes estruturais, é importante resgatar o ensinamento gramsciano sobre a criação de uma nova cultura.

Criar uma nova cultura não significa apenas fazer individualmente descobertas 'originais'; significa também, e sobretudo, difundir criticamente verdades já descobertas, 'socializá-las' por assim dizer; e, portanto, transformá-las em base de ações vitais, um elemento de coordenação e de ordem intelectual e moral. O fato de que uma multidão de homens seja conduzida a pensar coerentemente e de maneira unitária a realidade presente é um fato 'filosófico' bem mais importante e 'original' do que a descoberta, por parte de um 'gênio' filosófico, de uma nova verdade que permanece como patrimônio de pequenos grupos intelectuais (GRAMSCI, 1966, p.13-14). 
No âmbito das políticas sociais, particularmente, talvez a priorização do alcance de objetivos tenha sido responsável pelo esquecimento do processo educativo a ser percorrido na busca da sua efetividade, limitando a sua utilidade ao alcance do fim desejado. É preciso conjugar o alcance do objetivo com o processo para atingi-lo, transformando a trajetória da luta política em transformação e avanço de consciência. Entendemos que é exatamente essa perspectiva de processo de disputa, permeado de socialização de verdades, que pode criar as condições básicas para a efetivação das possibilidades do exercício do controle social democrático de políticas públicas.

\section{Possibilidades para o exercício do controle social de políticas públicas}

O desenvolvimento das ideias realizado até aqui permite afirmar que a sociedade brasileira, após a ascensão do Governo Bolsonaro ao poder, vive, como analisa Felipe Demier, uma "democracia blindada", que responde aos ditames impostos pelo sistema capitalista.

[...] tais democracias apresentam estruturas de funcionamento hermeticamente fechadas às pressões populares, preservando seus núcleos institucionais decisórios como espaços exclusivos dos interesses da classe dominante. Adequadas às necessidades da acumulação capitalista em tempos do tardio-capitalismo, as democracias blindadas combinam retiradas de direitos com a expansão com a expansão (maior ou menor, a depender do momento e do gestor de plantão de políticas sociais compensatórias, carentes de universalidade, além de um aumento seletivo de repressão estatal voltada aos setores indômitos. [...] essas democracias liberais contemporâneas, de tipo blindado, oferecem o que se pode chamar de uma nova forma de trato da velha 'questão social' por parte do estado capitalista (DEMIER, 2017, p. 33).

Dessa maneira, a forma mais evidente de controle experimentado pela sociedade, na atualidade, volta a ser aquele exercido pelo Estado sobre a sociedade civil. Um exemplo disso vem sendo inserido de forma persuasiva na politica de as- sistência social, em alguns municípios, que usam o CRAS como espaço para o desenvolvimento integrado de políticas de segurança pública.

Por meio de tal expediente, os CRAS assumem certo grau de responsabilidade pelo acompanhamento de pessoas em liberdade condicional, canalizando o tempo de profissionais para esse tipo de controle, em detrimento do desenvolvimento de ações socioeducativas. Assim, o avanço de um estado conservador e repressivo cria "novas formas" de enfrentamento da questão social e, enquanto restringe recursos para o investimento na segurança social, investe em tentativas destinadas à segurança pública. Esse desvio de foco busca deveras a contenção dos impactos da crise estrutural, destacando em um de seus efeitos - a violência - e reiterando a velha abordagem policialesca da questão social.

Diante desse contexto, entendemos que é urgente aos operadores das politicas sociais a retomada desse campo como espaço possivel para a criação de um pensamento contra-hegemônico, capaz de se expressar nos conselhos ainda existentes em nivel nacional, estadual, municipal e local, com competência crítica7, disputando, no jogo de interesses manifestos, cada proposta orçamentária ou programática e fiscalizando o uso dos recursos públicos. Além disso, é importante que o conselho seja um efetivo canal de comunicação com a sociedade civil, informando sobre o desenvolvimento das políticas e promovendo a sua mobilização em prol da defesa de uma adequada locação e uso de recursos financeiros para a prestação de serviços de qualidade.

Porém, para que o exercício do controle social democrático por meio dos conselhos possa se efetivar de forma qualificada como controle social democrático, terá que enfrentar muitos obstáculos, pois não só os setores governamentais, com suas lógicas de autoritarismo e clientelismo, senão que também a despolitização da sociedade civil se constituirão em entraves (CALVI, 2008).

\footnotetext{
7 Segundo Marilda lamamoto, a competência crítica significa o contrário da burocrática, sendo aquela que é "capaz de desvendar os fundamentos conservantistas e tecnocráticos do discurso da competência burocrática. O discurso competente é crítico quando vai à raiz e desvenda a trama submersa dos conhecimentos que explica as estratégias de ação. Essa crítica não é apenas mera recusa ou mera denúncia do instituído, do dado. Supõe um diálogo intimo com as fontes inspiradoras do conhecimento e com os pontos de vista das classes por meio dos quais são construidos os discursos" (IAMAMOTO, 2009, p. 2-3).
} 
E, como alerta Gramsci, "[d]eve-se notar que a elaboração das camadas intelectuais na realidade concreta não ocorre num terreno democrático abstrato, mas segundo processos históricos tradicionais muito concretos" (GRAMSCl, 2001, p. 20).

Portanto, é necessário também empreender um amplo movimento de politização dos setores populares, o que requer nesse contexto altamente desfavorável a qualquer iniciativa de educação popular, o uso de estratégias criativas. Somente assim será possivel trazer à tona a lógica perversa do capital e mobilizar consciências para uma organização coletiva de enfrentamento ao poder contrário ao atendimento das necessidades e interesses das classes subalternas. A politização dos setores populares é fundamental para a garantia da perspectiva de controle social democrático, conforme

inscrita na Constituição Federal de 1988, que vai enfatizar a participação dos setores organizados da sociedade civil, especialmente dos trabalhadores e dos segmentos populares, na elaboração e implementação das políticas públicas, propondo novas relações entre o movimento social e a esfera da politica institucional (RAICHELIS, 2011, p. 21)

Assim sendo, não é demais insistir que os conselhos não podem ser mecanismos que funcionem de forma isolada, como se apenas os conselheiros fossem os responsáveis pelo bom andamento das políticas das quais participam como representantes. Aliás, a reprodução de uma democracia representativa desvirtuada, como ocorre nos setores legislativos, onde o representante defende os seus próprios interesses e de seu pequeno círculo de amizades, tem sido um dos grandes empecilhos para o bom funcionamento dos conselhos.

Dessa forma, muitos deles se tornaram desacreditados, sendo considerados apenas como mais uma instância burocrática para aprovar e legitimar as decisões governamentais. Resgatar o significado original da criação dos conselhos é tarefa que se impõe no campo da política social, pois não basta não serem extintos, é preciso que a sua existência justifique a razão de sua criação.

A ênfase nos conselhos como uma das media- ções de resistência ativa pretende torná-los, também, instrumentos de ampliação da participação por meio do incentivo e apoio à organização de fóruns da sociedade civil, quer sejam de usuários ou de organizações não governamentais defensoras dos direitos dos usuários. Os fóruns podem se constituir em espaços formativos e de reunião de interesses comuns, para o fortalecimento das lutas encetadas nos conselhos ou para a ampliação de demandas. Aliás, a articulação entre os próprios conselhos setoriais é outra possibilidade de fortalecimento do controle social democrático, que pode contribuir para a diminuição da fragmentação de interesses sociais por meio de análises e proposições intersetoriais, que venham a fortalecer a ação em rede de serviços sociais, tendo em vista um atendimento mais globalizado, que pode contribuir para a percepção da raiz das manifestações da questão social.

É importante considerar, ainda, que o incentivo à participação em conselhos necessita chegar à base, isto é, lá onde os efeitos das políticas são percebidos de forma concreta, nas comunidades onde vivem os mais pobres. É no território dos CRASs e da maioria das UBSs que, de forma evidente, são percebidos os vazios, as fragilidades, as insuficiências, os desvios, das políticas públicas. Por isso, a organização de conselhos ou de comissões locais pode ser o grande dinamizador da prática conselhista e, principalmente, pode ser uma maneira de minar os municípios com pequenas células de circulação de conhecimento crítico sobre as políticas sociais e de organização popular. Como ensina Carlos Nelson Coutinho, bebendo da fonte de seu mestre Antonio Gramsci,

\begin{abstract}
as batalhas politicas devem ser travadas inicialmente no âmbito da sociedade civil, visando à conquista de posições e de espaços ("guerras de posições"), da direção político-ideológica e do consenso dos setores majoritários da população como condição para o acesso ao poder de Estado e para sua posterior conservação (COUTINHO, 2003, p. 29).
\end{abstract}

Entendemos que, para a classe subalterna conseguir romper com o ciclo de subalternidade, não basta oferecer meios que ajudem a minorar a sua pobreza, é preciso que de forma 
concomitante haja a sua politização, pois um adequado gerenciamento de políticas sociais pode ser perfeitamente funcional à manutenção do sistema, como já tem sido analisado amplamente por intelectuais de esquerda. Não basta o técnico compreender que está trabalhando para efetivar um direito, é preciso repassar esta concepção para as pessoas atendidas.

Combater o pensamento hegemônico sobre as politicas sociais como residuais e meritocráticas exige o aproveitamento e a ampliação de espaços de participação substantiva da população empobrecida, nos quais possa haver a politização das politicas, promovendo a educação de base e favorecendo o desenvolvimento de uma forma de pensar autônoma da ideologia dominante, pois "[a] consciência de fazer parte de uma determinada força hegemônica é a primeira fase de uma ulterior e progressiva autoconsciência, na qual a teoria e prática finalmente se unificam" (GRAMSCl, 1986 p. 21).

Se, por um lado, essas ideias podem parecer exigir o impossivel dos trabalhadores da área das políticas sociais, convém lembrar que há também sinais de resistência nesses tempos adversos a qualquer tipo de emancipação da classe subalterna. Destacamos, aqui, apenas dois deles, para reafirmar a possibilidade de resistir. Na XVI Plenária Nacional de Conselhos de Saúde ${ }^{8}$, realizada em 2019, ao realizar a análise da conjuntura política do SUS, o então presidente do Conselho Nacional da Saúde fez a seguinte pergunta:

Queremos de fato construir outro modelo de atenção à saúde, formando equipes multiprofissionais, com vínculo com os usuários, que se responsabilizam pela saúde da população, e que trabalham para que as pessoas tenham autonomia para viver suas vidas da melhor maneira possivel? Ou vamos assumir que a saúde é uma mercadoria, que deve ser consumida através de consultas médicas, exames e remédios?

Na área da Assistência Social, diante da posição contrária do governo e da consequente revogação das resoluções do CNAS, que convocavam a XII Conferência Nacional de Assistência Social, também no ano de 2019, ela foi convocada da seguinte maneira: ${ }^{9}$

Nós, organizações e movimentos sociais abaixo assinados, convocamos a Conferência Nacional Democrática de Assistência Social com o tema: "Assistência Social: Direito do Povo com Financiamento Público e Participação Social". [...] Consideramos de fundamental importância assegurar o ciclo de conferências, uma vez que estamos vivenciando o desmonte e o desfinanciamento da política pública de Assistência Social, comprometendo a sobrevivência de milhões de familias, agravada pelo avanço da pobreza, do desemprego e das desigualdades. Além disso, o ciclo de conferências é fundamental para a garantia do direito constitucional à participação e ao controle social.

E a referida Conferência foi realizada nos dias 25 e 26 de novembro de 2019, no auditório da Associação dos Docentes da Universidade de Brasilia, por meio de financiamento coletivo. Contou com a participação de 800 pessoas, entre gestores, usuários, trabalhadores, acadêmicos, integrantes dos movimentos sociais, entidades e/ou organizações da sociedade civil, frentes e fóruns.

Portanto, as possibilidades do exercício do controle social democrático podem ser efetivadas na resistência ativa e organizada de mecanismos de participação da sociedade civil, como conselhos e fóruns, na medida em que essas instâncias forem, concomitantemente ao exercício de suas atribuições especificas, mecanismos informativos e formativos, capazes de contribuir para uma nova consciência coletiva, que impulsione o processo emancipatório da classe subalterna. Isto é, quando a luta por políticas sociais eficazes for um meio para a criação de condições mais favoráveis à ruptura com os mecanismos reprodutores da desigualdade social.

\section{Considerações finais}

A estratégia argumentativa desenvolvida ao longo do presente artigo buscou jogar focos de luz sobre determinados pontos da complexa

8 Ver Análise da Conjuntura Politica do SUS. Disponivel em http://conselho.saude.gov.br/web_plenaria/Docs/ANALISE_DA_CONJUNTURA_POLITICA_DO_SUS. Acesso em: 15 maio 2019.

9 Ver Convocação da Conferência Nacional Democrática de Assistência Social. Disponivel em https://conferenciadeassistenciasociathome.files.wordpress.com/2019/08/versa04_cnas_convocacao. Acesso em: 19 maio 2019. 
composição da realidade brasileira, destacando aspectos que pudessem servir de apoio para a elucidação de potencialidades que podem - e precisam - ser incentivadas e desenvolvidas com relação à questão do controle social democrático das políticas públicas

Inicialmente, destacou-se que o atual momento do Estado nacional é da mais servil submissão possivel aos ditames da ordem econômica mundial. Nessa lógica, é responsável, não apenas pela extinção de algumas conquistas no campo dos direitos sociais e humanos, mas também pela disseminação da barbárie da vida social cotidiana, especialmente junto aos territórios onde vive a população pobre, negra e indigena.

Como ferramenta de análise de tal realidade, o conceito de democracia blindada, proposto por Demier (2017), evidenciou a magnitude dos desafios para o exercício do controle social de políticas públicas, ao dar a dimensão de uma quase impossibilidade de ruptura da institucionalidade conservadora e autoritária, que permeia toda a ação estatal na atualidade, incluindo as políticas sociais. No entanto, entendemos que é exatamente a existência do desafio que pode mover a intensificação de espaços de fortalecimento da participação popular, habilitando-a para o enfrentamento com os defensores dos interesses das classes dominantes.

Assim, como polo contrário e força de reação aos desafios, apresentamos duas linhas complementares e articuladas de potencialização do controle social democrático das políticas públicas.

Numa primeira direção, julgamos necessário que o exercício do controle social democrático busque garantir o amplo acesso da população aos direitos sociais, por meio de serviços qualificados. Entretanto, embora necessário, isso não é suficiente. A despeito do reconhecimento de que as práticas conselhistas são fundamentais, importa sublinhar que, a fim de que o exercício do controle social das políticas públicas possa impactar concretamente a proposição e a implementação das políticas sociais, ele necessita expandir-se para fóruns, comissões e conselhos locais, enraizando-se na base do tecido social.
Numa segunda direção, absolutamente articulada à anterior, julgamos ser fundamental revestir as práticas de controle social democrático do caráter de educação popular. Para isso, entendemos que é preciso, também, estender o exercício do controle social, inserindo-o nos espaços de prestação de serviços sociais, a fim de que as políticas sociais passem a ser não somente objeto de consumo dos usuários, mas também de reflexão, aquisição de conhecimento e mudança. Quanto mais os operadores das políticas despenderem tempo em ações educativas, maior será o ganho da política como conquista, em detrimento do ganho político de legitimação do poder governamental. Assim, trava-se a luta também no campo das consciências.

Por fim, salientamos que seria ingenuidade considerar o campo das políticas sociais como espaço capaz de, por si só, reverter o sistema dominante. Isso, no entanto, não impede de reconhecê-lo como espaço possivel de emancipação e de obtenção de melhorias concretas nas condições de vida dos subalternos, desde que sejam democratizados e democratizantes.

Dito de outro modo, o campo das políticas sociais e nele o controle social democrático das políticas públicas poderá desenvolver seu potencial emancipatório na medida em que se constituir como espaço fértil para a politização e a organização da classe subalterna. Isto é, quando o exercício do controle social transcorrer paralelamente como processo de educação popular.

\section{Referências}

BRAVO, Maria Inês. Conferência II: Potencialização das Representações do Conjunto CFESS/CRESS nos Conselhos de Politicas e de Direitos. In: SEMINÁRIO NACIONAL "O CONTROLE SOCIALE A CONSOLIDAÇÃO DO ESTADO DEMOCRÁTICO DE DIREITO", 2011, Brasilia, DF. Anais [...]. Brasilia, DF: CFESS, 2011. p. 53-67. Disponivel em: http:// www.cfess.org.br/arquivos/livrosite_seminariocontrolesocialCFESS-CRESS. Acesso em: 10 dez. 2019

CALVI, K. U. O controle social nos conselhos de politicas e de direitos. Emancipação, Ponta Grossa, v. 8, n. 1, p. 9-20, jan./jun. 2008. https://doi.org/10.5212/ Emancipacao.v.8i1.009020.

COUTINHO. Carlos. N. Um estudo sobre o pensamento politico. Rio de Janeiro, Civilização Brasileira, 2003 
DEMIER, Felipe. Depois do golpe: a dialética da democracia blindada no Brasil. Rio de Janeiro: Mauad X, 2017.

GUERRA, André; BARBOSA, Cláudia. Crítica e pós-verdade. In: GUARESCHI, Pedrinho Arcides; AMON, Denise; GUERRA, André (org.). Psicologia, Comunicação e Pós-Verdade. Florianópolis: ABRAPSO, 2017. p. 101-151.

IAMAMOTO, Marilda Villela. O Serviço Social na cena contemporânea. In: Serviço Social: Direitos e Competências profissionais. Brasilia: CFESS/ABEPSS, 2009. p.15-45.

GIOVANNI, Geraldo Di. As estruturas elementares das políticas públicas. Cadernos de Pesquisa. Campinas, Universidade Estadual de Campinas - UNICAMP. Núcleo de Estudos de Políticas Públicas - NEPP, n. 82, p. 101-151, 2009. Disponivel em: www.bibliotecadigital. unicamp.br. Acesso em: 20 nov. 2019.

GOHN, Maria da Gloria. Conselhos Gestores e Participação Sociopolítica. São Paulo: Cortez, 2001.

GRAMSCl, Antonio. Cadernos do cárcere. Tradução de Carlos Nelson Coutinho com a colaboração de Luiz Sergio Henriques e Marco Aurélio Nogueira. Rio de Janeiro: Civilização Brasileira, 2000. v. 3

GRAMSCI, Antonio. A concepção dialética da história. 6. ed. Tradução de Carlos N. Coutinho. Rio de Janeiro: Civilização Brasileira, 1986.

GRAMSCl, Antonio. Cadernos do cárcere. 2. ed. Rio de Janeiro: Civilização Brasileira, 2001. v. 2.

LARA, Ricardo; MARANHÃO, Cézar. Fundamentos do trabalho, "questão social" e serviço social. In: SOUZA, Edvânia A.; SILVA, Maria Liduina de Oliveira (org.). Trabalho, questão social e serviço social: a autofagia do capital. São Paulo: Cortez, 2019. p. 37-61.

RAICHELIS, Raquel. Conferência I: O Controle Social Democrático na Gestão e Orçamento Público 20 Anos Depois. In: SEMINÁRIO NACIONAL "O CONTROLE SOCIAL E A CONSOLIDAÇÃO DO ESTADO DEMOCRÁTICO DE DIREITO", 2011, Brasília, DF. Anais [...]. Brasília, DF: CFESS, 2011. p.19-31 Disponivel em: http://Www.cfess. org.br/arquivos/livrosite_seminariocontrolesocialCFESS-CRESS. Acesso: em 17 dez. 2019.

VEIGA, Edison. Desmatamento: Amazônia perdeu 20\% e Cerrado, 50\%, desde 1970, aponta relatório do WWF. Disponivel em: https://Www.bbc.com/portuguese/ brasil-46026334. Acesso em: 12 nov. 2019.

\section{Vini Rabassa da Silva}

Professora do Curso de serviço Social da UCPEL e do Programa de Pós-Graduação em Política Social e Direitos Humanos.

\section{Mara Rosange Acosta de Medeiros}

Professora do Curso de Serviço Social e do Programa de Pós-Graduação em Política Social e Direitos Humanos da UCPEL. Doutora em Serviço Social/PUCRS.

\section{Endereço de correspondência}

Vini Rabassa da Silva

Universidade Católica de Pelotas - Campus I

Rua Gonçalves Chaves, 373

96015-560 - Centro - Pelotas/RS 